\title{
Impact of Vitamin C as an Adjuvant Agent on Glycemic Indices in Type 2 Diabetes Mellitus: Randomized Clinical Trial
}

\author{
Shabzain Ishrat, Talea Hoor, Muhammad Sajid Abbas Jaffri, Shizma Junejo, Mehreen Lateef
}

\section{ABSTRACT}

Objectives: To evaluate the effects of adjuvant vitamin C therapy with oral hypoglycemic on FBS, RBS and HbA1c and to find out the correlation of Vitamin $\mathrm{C}$ with glycemic indices.

Study Design \& Settings: This randomized open label clinical trial was conducted at Bahria University Medical \& Dental College (BUMDC) in collaboration with NMC, Karachi from October 2018 to April 2019.

Methodology: A total of 160 known type -2 males and females, uncomplicated diabetics, aged 40-65 years with FBS= $200 \mathrm{mg} / \mathrm{dl}, \mathrm{HbA} 1 \mathrm{c}=8.5 \%$ and diabetes duration $>5$ years were enrolled from diabetic clinic of NMC after written informed consent. They were divided into control group and treatment group by sealed envelope technique. Control group received oral hypoglycemic drugs while treatment group received vitamin C $500 \mathrm{mg}$ per orally BD with oral hypoglycemic drugs with advice of diet control and daily exercise. Patients were subjected to FBS, RBS and HbAlc at baseline and at the end of 90 days. SPSS version 23.0 was used for data analysis. The results were expressed as mean \pm standard deviation (SD). $P$ value $<0.05$ was considered as statistically significant.

Results: In control group FBS and RBS reduced by $1 \mathrm{mg} / \mathrm{dl}$ and $7 \mathrm{mg} / \mathrm{dl}$ from day- 0 to 90 . In treatment group FBS reduced by $14 \mathrm{mg} / \mathrm{dl}$ and RBS reduced by $21 \mathrm{mg} / \mathrm{dl}$ from day- 0 to 90 . HbA1c increased by $0.7 \%$ in control group and decreased by $0.4 \%$ in treatment group at the end of 90 days. Negative correlation is observed between Vitamin $\mathrm{C}$ and glycemic indices.

Conclusion: Adjuvant vitamin C therapy with oral hypoglycemic drugs in type-2 diabetics reduced FBS, RBS and HbAlc and exhibited negative correlation with glycemic parameters.

Keywords: Correlation, Fasting blood sugar, HbA1c, Random blood sugar, Type 2 diabetes mellitus, Vitamin C.

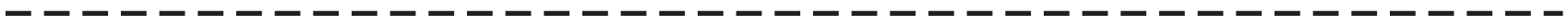

How to cite this Article:

Ishrat S, Hoor T, Jaffri MSA, Junejo S, Lateef M. Impact of Vitamin C as an Adjuvant Agent on Glycemic Indices in Type 2 Diabetes Mellitus: Randomized Clinical Trial. J Bahria Uni Med Dental Coll. 2021; 11(3):102-106 DOI: https://doi.org/10.51985/MYDD5410

This is an Open Access article distributed under the terms of the Creative Commons Attriution Non Commercial Liciense (http///creativecommons/org/licences/by-nc/4.0) which permits unrestricted non commercial use, distribution and reproduction in any medium, provided the original work is properly cited.

ー - - - - - - - - - - - - - - - - - - - - - - - - -

\section{INTRODUCTION:}

Diabetes mellitus (DM) is a metabolic disorder characterized by elevated levels of blood glucose. It is one of the oldest diseases known to mankind. ${ }^{1}$ Type $2 \mathrm{DM}$ is characterized by hyperglycemia, hyperlipidemia, insulin resistance etc; caused by gradual destruction of â cells. ${ }^{2,3,4,5}$ It accounts for

г- - - - - - - - - - - - - ר

Shabzain Ishrat

Senior Demonstrator, Department of Pharmacology,

I Shahida Islam Medical and Dental College, Lodhran

Email: ishabzain@hotmail.com

I Talea Hoor

Professor, Department of Pharmacology,

I Bahria University Medical and Dental College, Karachi

I

Muhammad Sajid Abbas Jaffri

Professor, Department of Medicine,

I Bahria University Medical and Dental College, Karachi

I Shizma Junejo

I Senior Lecturer, Department of Biochemistry,

I Bahria University Medical and Dental College, Karachi

I Mehreen Lateef

Assistant Professor, Department of MDRL,

Bahria University Medical and Dental College, Karachi

Received: 28-10-2020

Accepted: 14-06-2021
$90 \%$ to $95 \%$ of the diabetic patients. ${ }^{6,7}$ International Diabetes Federation (IDF) has estimated that 1 in 11 adults were diagnosed with type $2 \mathrm{DM}$ in 2015 and has predicted that there will be 642 million people with type 2 DM in 2045. The disease is more common in developing countries as compared to developed nations. ${ }^{8}$ According to IDF, Pakistan has high prevalence of disease and is in the list of top ten countries with increased prevalence of type $2 \mathrm{DM}$. About 6.6 million people live with type 2 diabetes in Pakistan. ${ }^{9}$ Pakistan is the sixth most populous country and the trend for urbanization has increased in the recent years. Sedentary lifestyle, increased consumption of high calorie diet, lack of exercise and stressful conditions has led to increased prevalence of disease in Pakistan. ${ }^{10}$ Long standing hyperglycemia of type 2 diabetes mellitus leads to increase in oxidative stress by production of reactive oxygen species. These reactive oxygen species lead to progression of disease into complicated diabetes mellitus which includes microvascular and macro-vascular complications. ${ }^{11}$ It has been reported by various studies that there is a strong association between oxidative damage and progression of disease. The imbalance between the rate of production of reactive oxygen species and to counteract them by antioxidants is the main 
Impact of Vitamin C as an Adjuvant Agent on Glycemic Indices in Type 2 Diabetes Mellitus: Randomized Clinical Trial

factor behind continuous oxidative damage in type $2 \mathrm{DM}$.

Researches are being conducted globally to effectively control the glycemic indices so as to prevent and/or control the complications associated with type -2 diabetes and hence to reduce morbidity and mortality. ${ }^{11}$ Co-administration of vitamin $\mathrm{C}$ along with drug treatment of type 2 diabetes mellitus might facilitate the control of glycemic indices. Therefore, present study was conducted to evaluate the effects of vitamin $\mathrm{C}$ on glycemic control in type 2 diabetes mellitus and to find out the correlation of vitamin $\mathrm{C}$ with the glycemic indices.

\section{METHODOLOGY:}

This randomized clinical trial was conducted from October 2018 to April 2019 after ethical approval numbered ERC 50/2018 from BUMDC and FRC in collaboration with diabetic clinic of National Medical Centre (NMC), Karachi.

Patients with known history of diabetes without complications, aged 40 to 65 years, both male and female with $\mathrm{FBS}=200 \mathrm{mg} / \mathrm{dl}, \mathrm{HbA1C}=8.5 \%$, normal baseline investigations of LFTS, RFTS, diabetes duration $>5$ years, no history of intake of vitamin $C$ or other antioxidant vitamins at least three months prior to start of study and absence of diabetic complications, were included in the study. Patients with other types of diabetes and systemic diseases, pregnancy, lactating mothers, smokers, altered LFTs and RFTs were excluded. All patients were thoroughly examined by the consultant diabetologist to rule out the presence of complication(s) clinically before subjecting them to laboratory investigations at baseline and at the end of three months that is evaluation of fasting blood sugar, random blood sugar and glycosylated hemoglobin from Pathology laboratory of NMC, on Roche Cobas 6000 series (c 501) chemistry analyzer. Vitamin $\mathrm{C}$ analysis was performed at the Multidisciplinary Research laboratory (MDRL) of BUMDC by Human Vitamin C ELISA kit number DRE67468, Glory science, China. The calculated sample size was 140 by using the formula for prevalence. After obtaining written informed consent a total of $\mathrm{n}=160$ were enrolled and divided into control group and treatment group with 80 participants each using sealed envelope technique. The patients in treatment group were prescribed vitamin C $500 \mathrm{mg}$ twice daily per orally for three months along with their oral antidiabetic drugs. The patients in control group were prescribed the same except vitamin C. All patients were advised for life style changes with standard dietary charts for type 2 diabetes mellitus and 30-40 minutes brisk walking daily. The oral antidiabetic drugs included combination therapy which dipeptidyl peptidase 4 (DPP4) inhibitors and metformin in 50/500 or 50/850 mg twice daily depending upon there glycemic index. The data was entered on SPSS version 23 for data analysis. The results were expressed as mean \pm standard deviation (SD). After checking the normality of data the comparison between treatment group and control group was performed by independent sample $t$ test. Paired analysis in between the treatment group was done by paired sample $t$ test. The Pearson's correlation was applied to determine the relationship between vitamin $\mathrm{C}$ and $\mathrm{HbAlc}$, FBS and RBS variables. After checking Pearson's correlation linear regression was analyzed. Significant differences were considered at $\mathrm{p}$ value $<0.05$.

\section{RESULTS:}

Total $n=140$ subjects completed the study and their data was analyzed for present study. Chi square homogeneity test revealed no significant difference in duration of diabetes mellitus between control and treatment group. The age of treatment group and control group ranged from 40 to 65 years with a mean of $50.65 \pm 7.96$ and $50.58 \pm 9.10$ respectively. From 140 subjects 82 (59\%) subjects were females and 58 (41\%) were males. Anthropometric measurements (pulse, BMI, blood pressure, weight and height) showed no significant difference between control and treatment groups.

The Paired sample $t$ test was applied for the analysis of paired observations of fasting blood sugar, random blood sugar, $\mathrm{HbA} 1 \mathrm{c}$ and vitamin $\mathrm{C}$ between day 0 and day 90 . Table 1 shows the comparison of glycemic parameters between day 0 and day 90 of treatment group. The vitamin $\mathrm{C}$ level at day 0 in treatment group was $0.25 \mathrm{mg} / \mathrm{dl}$ and at day 90 was $1.4 \mathrm{mg} / \mathrm{dl}$. There was significant difference $(p<0.001)$ in levels of FBS, RBS and HbA1c at day 90 in treatment group after administration of vitamin C $500 \mathrm{mg}$ twice daily for three months.

The comparison of glycemic parameters between control and treatment group was performed by Independent sample $\mathrm{t}$ test. Table 2 shows the results of glycemic parameters and vitamin $\mathrm{C}$ comparison between control and treatment group.

AST level showed significant difference but there was no significant difference in ALT and bilirubin in treatment group at three months after administration of vitamin $\mathrm{C}$ however ALT, AST and bilirubin showed insignificant difference between control and treatment group. RFTS (urea and creatinine) showed non- significant difference between control and treatment group and in between treatment group.

The Pearson's correlation coefficient was used to determine the association between independent variable vitamin $\mathrm{C}$ and dependent variables FBS, RBS and HbA1c. Table 3 shows the results of Pearson's correlation between vitamin $C$ and FBS, RBS and HbA1c. There was a statistical significant moderate negative correlation between vitamin $\mathrm{C}$ concentration and HbA1c levels $r_{s}=-0.465, \mathrm{p}<0.001$; statistical significant weak negative correlation between vitamin $\mathrm{C}$ concentration and RBS levels $r_{s}=-0.364, \mathrm{p}=$ 0.002; statistical significant moderate negative correlation between vitamin C concentration and FBS levels $r_{s}=-0.435$, $\mathrm{p}<0.001$.

Linear regression was performed to check the degree of association of independent variable vitamin $\mathrm{C}$ and dependent variables FBS, RBS and $\mathrm{HbA1c}$. Table 4 shows the results 
Shabzain Ishrat, Talea Hoor, Muhammad Sajid Abbas Jaffri, Shizma Junejo, Mehreen Lateef

of linear regression. A linear regression was established that vitamin $\mathrm{C}$ given for three months in divided doses of 500 $\mathrm{mg}$ twice daily accounted for $27.4 \%$ of variation in fasting blood sugar with adjusted $R^{2}=26.3 \% ; 23.6 \%$ variation in random blood sugar with adjusted $R^{2}=22.5 \%$ and $37 \%$ variation in $\mathrm{HbA} 1 \mathrm{c}$ with adjusted $R^{2}=36.1 \%$. Vitamin C given for three months in divided doses significantly reduced FBS levels, $F(1,70)=26.4, p<0.001$; RBS levels, $F(1,70)$ $=21.6, p<0.001$ and HbA1c levels, $F(1,70)=41.1, p<$ 0.001 .

Table 1: Treatment group comparison between day 0 and day 90 of laboratory parameters $(\mathrm{N}=70)$

\begin{tabular}{|c|c|c|c|}
\hline Parameter & $\begin{array}{c}\text { Day 0 } \\
(\text { Mean } \pm \text { SD })\end{array}$ & $\begin{array}{c}\text { Day 90 } \\
(\text { Mean } \pm \text { SD }) \\
\end{array}$ & P-value \\
\hline FBS (mg/dl) & $139 \pm 29$ & $125 \pm 25$ & $\mathrm{P}<0.001$ \\
\hline RBS (mg/dl) & $208 \pm 45$ & $187 \pm 34$ & $\mathrm{P}<0.001$ \\
\hline HbA1c (\%) & $7.9 \pm 0.5$ & $7.5 \pm 0.7$ & $\mathrm{P}<0.001$ \\
\hline ALT (IU/L) & $31.8 \pm 7.1$ & $31.6 \pm 6.1$ & 0.84 \\
\hline AST (IU/L) & $24.6 \pm 6.5$ & $23.0 \pm 5.8$ & $\mathrm{P}<0.05$ \\
\hline Bilirubin (mg/dl) & $0.6 \pm 0.1$ & $0.6 \pm 0.1$ & 0.55 \\
\hline Urea $(\mathrm{mg} / \mathrm{dl})$ & $31.5 \pm 7.8$ & $30.4 \pm 7.1$ & 0.09 \\
\hline Creatinine $(\mathrm{mg} / \mathrm{dl})$ & $0.8 \pm 0.1$ & $0.7 \pm 0.1$ & 0.64 \\
\hline Vitamin C (mg/dl) & $0.25 \pm 0.29$ & $1.42 \pm 0.91$ & $\mathrm{P}<0.001$ \\
\hline
\end{tabular}

Key: FBS: Fasting blood sugar, RBS: Random blood sugar, HbA1c: Glycosylated hemoglobin, ALT: alanine aminotransferase, AST: aspartate aminotransferase $* \mathrm{~N}=$ Number of subjects, Test applied: Paired sample t test

\section{DISCUSSION:}

About $25 \%$ of the newly diagnosed patients already have developed one or more complications of diabetes mellitus. ${ }^{12}$ Hyperglycemia in long standing diabetes mellitus is a continuous source of oxidative stress which plays an important role in development of complications. Oxidative damage leads to production of glycosylated products and other advanced glycation end products (AGEs). Lipid peroxidation also occurs as a result of long standing hyperglycemia. ${ }^{13}$ Other pathways implicated in increased oxidative damage in type 2 DM include glucose autooxidation, polyol pathway and protein kinase isoforms activation. ${ }^{14}$ These all processes are continuous source of oxidative damage leading to endothelial damage and micro vascular complications. ${ }^{15}$ Along with increased oxidative stress in type $2 \mathrm{DM}$ the antioxidant system is also not functioning as the levels of antioxidants is less. Vitamin C is an important antioxidant that helps to diminish the oxidative damage and plays an important role in various reactions. ${ }^{16}$ It is hydrophilic and soluble in water. Humans are unable to synthesize vitamin $\mathrm{C}$ endogenously as they lack Lgluconolactone oxidase.

Vitamin $\mathrm{C}$ is a six carbon lactone ring with 2,3- enediol moiety which provides antioxidant properties. It has structural similarity to glucose and replaces many reactions in the body. ${ }^{17}$ This vitamin, also called as ascorbic acid, was discovered by Hungarian biochemist Albert Szent Gyorgyi and is involved in many important functions in the human

Table 2: Comparison of laboratory parameters between control and treatment group at day 0 and $90(\mathrm{~N}=140)$

\begin{tabular}{|l|c|c|c|c|c|}
\hline \multirow{2}{*}{ Parameters } & \multicolumn{2}{|c|}{ Control group } & \multicolumn{2}{c|}{ Treatment group } & \multirow{2}{*}{} \\
\cline { 2 - 5 } & $\begin{array}{c}\text { Day 0 } \\
(\text { Mean } \pm \text { SD })\end{array}$ & $\begin{array}{c}\text { Day 90 } \\
(\text { Mean } \pm \text { SD })\end{array}$ & $\begin{array}{c}\text { Day 0 } \\
(\text { Mean } \pm \text { SD })\end{array}$ & $\begin{array}{c}\text { Day 90 } \\
(\text { Mean } \pm S D)\end{array}$ & \\
\hline FBS (mg/dl) & $142 \pm 25$ & $141 \pm 20$ & $139 \pm 29$ & $125 \pm 25$ & $<0.001$ \\
\hline RBS (mg/dl) & $202 \pm 41$ & $195 \pm 34$ & $208 \pm 45$ & $187 \pm 34$ & $>0.05$ \\
\hline HbA1c (\%) & $7.7 \pm 0.6$ & $8.4 \pm 0.8$ & $7.9 \pm 0.5$ & $7.5 \pm 0.7$ & $<0.001$ \\
\hline ALT (IU/L) & $30.5 \pm 10.4$ & $29.25 \pm 7.1$ & $31.8 \pm 7.1$ & $31.6 \pm 6.1$ & 0.60 \\
\hline AST (IU/L) & $24.5 \pm 8.7$ & $23.1 \pm 5.6$ & $24.6 \pm 6.5$ & $23.0 \pm 5.8$ & 0.93 \\
\hline Bilirubin (mg/dl) & $0.5 \pm 0.2$ & $0.5 \pm 0.1$ & $0.6 \pm 0.1$ & $0.6 \pm 0.1$ & 0.08 \\
\hline Urea (mg/dl) & $30.9 \pm 8.0$ & $31.0 \pm 8.1$ & $31.5 \pm 7.8$ & $30.4 \pm 7.1$ & 0.40 \\
\hline Creatinine (mg/dl) & $0.8 \pm 0.1$ & $0.7 \pm 0.1$ & $0.8 \pm 0.1$ & $0.7 \pm 0.1$ & 0.69 \\
\hline Vit C (mg/dl) & $0.26 \pm 0.45$ & $0.25 \pm 0.36$ & $0.25 \pm 0.29$ & $1.4 \pm 0.9$ & $<0.001$ \\
\hline
\end{tabular}

Key: FBS: fasting blood sugar, RBS: Blood sugar random, HbA1c: glycosylated hemoglobin, ALT: Alanine aminotransferase, AST: Aspartate aminotransferase, Test applied: Independent $\mathrm{T}$ test

Table 3: Pearson's correlation coefficient between independent variable vitamin $\mathrm{C}$ and dependent variables HbA1c, RBS and FBS in treatment Group

\begin{tabular}{|c|c|c|c|}
\hline Independent variable & Dependent variable & Correlation coefficient $\left(\boldsymbol{r}_{\boldsymbol{s}}\right)$ & P value \\
\hline Vitamin C & HbA1c & -0.465 & $<0.001$ \\
\hline Vitamin C & RBS & -0.364 & 0.002 \\
\hline Vitamin C & FBS & -0.435 & $<0.001$ \\
\hline
\end{tabular}


Figure1: Scatter plot with line of best fit showing $\mathrm{R}^{2}$ linear $=0.370$ between vitamin $\mathrm{C}(\mathrm{mg} / \mathrm{dl})$ and $\mathrm{HbA} 1 \mathrm{c}(\%)$

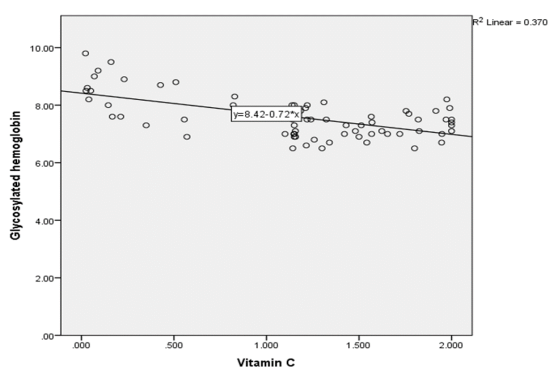

Figure 2: Scatter plot with line of best fit showing $\mathrm{R}^{2}$ linear $=0.236$ between vitamin $\mathrm{C}(\mathrm{mg} / \mathrm{dl})$ and random blood sugar $(\mathrm{mg} / \mathrm{dl})$

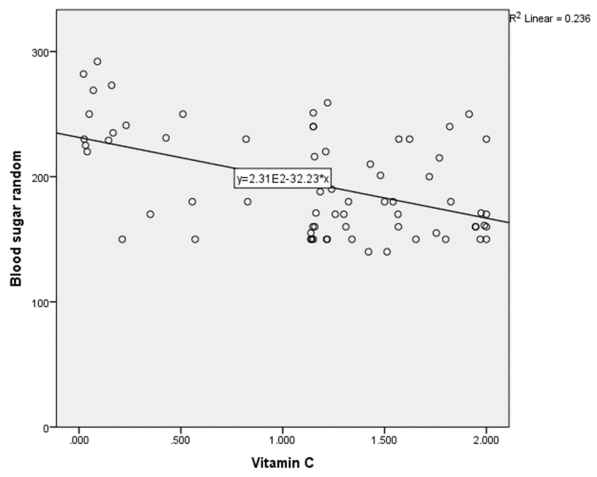

Figure 3: Scatter plot with line of best fit showing $\mathrm{R}^{2}$ linear $=0.274$ between vitamin $\mathrm{C}(\mathrm{mg} / \mathrm{dl})$ and fasting blood

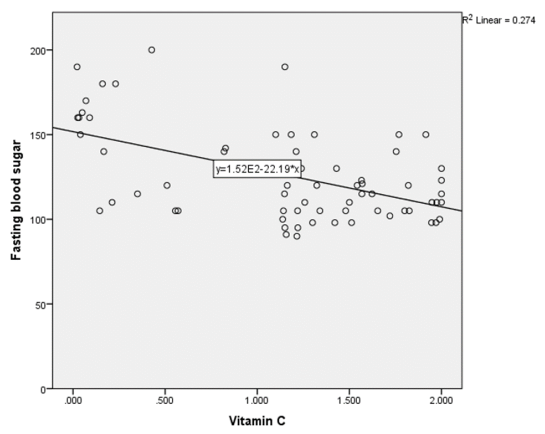

body. Antioxidant activity plays an important part in scavenging free radicals. ${ }^{18}$ It is also needed in tissue repair processes. Dietary sources are the natural means of ascorbic acid of which the citrus fruits and green leafy vegetables are richest source. Other sources include animal food of which the liver is important source. Animals usually synthesize this vitamin which then concentrates in the liver. The estimated average requirement (EAR) of vitamin $\mathrm{C}$ for adult men and women age $=19$ years is $30 \mathrm{mg} /$ day while recommended dietary allowance (RDA) for adult men and women aged $=19$ years is $45 \mathrm{mg} /$ day. The upper intake level which has no adverse effects for adult men and women aged $=19$ years is $2000 \mathrm{mg} /$ day. ${ }^{19}$

Hence this study was conducted to evaluate the effects of vitamin $\mathrm{C}$ therapy along with oral hypoglycemic drugs on the glycemic indices in type 2 diabetic patients and to find out the correlation of vitamin $\mathrm{C}$ with the glycemic indices.

The present work showed that vitamin $\mathrm{C}$ administration in a dosage of $500 \mathrm{mg}$ along with antidiabetic drugs decreased the fasting blood sugar, random blood sugar and HbA1c after three months. This work is supported by the study of Ali et al., in which significant difference $(p<0.05)$ was seen in the FBS and HbA1c both between treatment and control groups and within the treatment group. ${ }^{20}$ Mason et al. found non-significant difference in FBS and HbA1c after 4 months of administration of vitamin C $500 \mathrm{mg}$ twice daily contradictory to our study but found significant difference in random blood sugar supporting our study. ${ }^{21}$ Gillani et al., also found significant difference in FBS and $\mathrm{HbA} 1 \mathrm{c}$ after administration of $500 \mathrm{mg}$ once daily vitamin $\mathrm{C}$ for 12 months. ${ }^{22}$ Okafor et al. found significant differences in random blood sugar after administration of vitamin C 600 $\mathrm{mg}$ thrice daily in a treatment group. ${ }^{23}$ Our study showed similar and non- significant difference in AST results in both groups. Urea and creatinine in present study showed no significant difference in between the treatment group and control group indicating that co-administration of Vitamin $\mathrm{C}$ with oral hypoglycemic drugs is safe for use and does not produce any untoward effects in the diabetic patients upon administration. Ali et al., also found similar results for ALT, AST, urea and creatinine in their study. ${ }^{20}$ Mason et al., found supporting results with our study in which there was no significant difference compared to control group. ${ }^{21}$ This study found moderate negative correlation between vitamin $\mathrm{C}$ and FBS. Mahmouabadi and Rahbar also found significant negative correlation between vitamin $\mathrm{C}$ and FBS. They also found significant reduction in $\mathrm{HbA} 1 \mathrm{c}$ by $9 \% .{ }^{24}$ In our study $\mathrm{HbA} 1 \mathrm{c}$ was reduced by $0.4 \%$ in the treatment group. Another study by Kotb also showed significant negative correlation between vitamin $\mathrm{C}$ and FBS in which FBS was reduced by $25 \mathrm{mg} / \mathrm{dl}$ after three months of administration of vitamin $\mathrm{C}$, whereas we have found a reduction of $14 \mathrm{mg} / \mathrm{dl}$. They also found significant reduction in random blood sugar by $20 \mathrm{mg} / \mathrm{dl}$, whereas we have observed a decline of $21 \mathrm{mg} / \mathrm{dl}$ and in $\mathrm{HbAlc}$ there is a reduction of $1.59 \% .{ }^{25}$ However in our study, HbA1c was reduced by $0.4 \%$ as mentioned above. This could be because of more strict diet control and pattern of exercise followed by the patients of Kotb in comparison to our study. This study was done at a single center and was an open label clinical trial with small sample size.

\section{CONCLUSION:}

Co-administration of vitamin $\mathrm{C}$ with oral antidiabetic therapy has produced beneficial effects on the glycemic indices by reducing them from baseline. Negative correlation has been found between vitamin $\mathrm{C}$ and glycemic indices. Future studies with large sample size and at multiple centers may be conducted to authenticate the results of present study. 
Shabzain Ishrat, Talea Hoor, Muhammad Sajid Abbas Jaffri, Shizma Junejo, Mehreen Lateef

I Authors Contribution:
I Erum Behroz Khan: Concept, Study Design and Critical
Revision
I Samar Fatima: Drafting, concept, study design, data analysis I
I and interpretation
Mairah Shah: Data Analysis
Zuhair Ahmed: Data interpretation
I Sohail Khan: Data Analysis
I Sunia: Data interpretation

\section{REFERENCES:}

1. Sin YT, Joyce LMW, Yan JS, Su SW, Safa AME, Sean HT et al. Type 1 and 2 diabetes mellitus: A review on current treatment approach and gene therapy as potential intervention. Diabetes \& Metabolic Syndrome: Clinical Research \& Reviews 2018; 13(1): 364-372. doi: 10.1016/j.dsx.2018.10.008.

2. Jay SS, George LB, Ezio B, Tamara D, Robert HE, Leif G et al.. Differentiation of Diabetes by pathophysiology, natural history, and prognosis. Diabetes 2017; 66: 241-255. doi: 10.2337/db16-0806

3. Steven EK, Mark EC, Stefano DP. Pathophysiology and treatment of type 2 diabetes: perspectives on the past, present, and future. Lancet 2014; 383: 1068-83. doi: 10.1016/S01406736(13)62154-6.

4. Susanna D, Parinya C. The double burden of diabetes and global infection in low and middle income countries. Trans R Soc Trop Med Hyg 2019; 113: 56-64. doi: 10.1093/trstmh/ try 124.

5. American Diabetes Association. Classification and diagnosis of Diabetes: Standards of medical care in Diabetes 2020. Diabetes Care 2020; 43(Suppl. 1): S14-S31. https://doi.org/10.2337/dc20-S002

6. Paul ZZ, Dianna JM, William HH, Jonathan ES. Diabetes: a 21st century challenge. Lancet Diabetes Endocrinol 2014; 2: 56-64. doi: 10.1016/S2213-8587(13)70112-8.

7. Yanling W, Yanping D, Yoshimasa T, Wen Z. Risk factors contributing to type 2 Diabetes and recent advances in the treatment and prevention. Int J Med Sci 2014; 11(11): 11851200. doi: 10.7150/ijms.10001

8. Yan Z, Sylvia HL, Frank BH. Global aetiology and epidemiology of type 2 diabetes mellitus and its complications. Nature Reviews 2018; 14: 88-98. doi: 10.1038/nrendo. 2017.151.

9. Asima Z, Attya B, Fazal J, Xingbin W, Peter J, Aysha K et al. Prevalence of type 2 diabetes-associated complications in Pakistan. International Journal of Diabetes in Developing Countries 2015; 36(2): 179-188. Doi 10.1007/s13410-0150380-6

10. Sultan AM, Inam Z, Ishfaq AB, Shoukat AA. Type 2 diabetes mellitus in Pakistan: Current prevalence and future forecast. J Pak Med Assoc 2016; 66(12): 1637-1642.

11. Konstantinos P, Maciej B, Eleni B, Manfredi R, Michael E. Complications of Diabetes 2017. Journal of Diabetes Research 2018; 2018. Available from https://doi.org/10.1155/2018/ 3086167 Accessed on: 31-10-2020

12. Charles F, Alexandra K, Konstantinos I, Pavlos D, Manolis K, Kiriakos D. Microvascular complications of type 2 Diabetes Mellitus. Current Vascular Pharmacology 2020; 18(2): 117124. Doi $10.2174 / 1570161117666190502103733$
13. Shakir K, Abdul KN, Faizania S, Tausif AR, Muhammad JY. Oxidative stress in patients with type 2 Diabetes Mellitus. Journal of Rawalpindi Medical College 2014; 18(1): 29-31.

14. Surapon T. Oxidative stress, insulin resistance, dyslipidemia and type 2 diabetes mellitus. World Journal of Diabetes 2015; 6(3): 456-480. doi: 10.4239/wjd.v6.i3.456.

15. Asmat U, Abad K, Ismail K. Diabetes mellitus and oxidative stress-A concise review. Saudi Pharmaceutical Journal 2016; 24: 547-553. doi: 10.1016/j.jsps.2015.03.013.

16. Renée W, Jinny W, Richard G, Paula S, Elizabeth F, Chris F et al. Inadequate Vitamin $\mathrm{C}$ status in prediabetes and type 2 Diabetes Mellitus: Associations with glycaemic control, obesity and smoking. Nutrients 2017; 9(997): doi:10.3390 /nu9090997

17. Abolfazl A, Gholamali J, Saeed N, Javad S. An overview of the characteristics and function of Vitamin $\mathrm{C}$ in various tissues: Relying on its antioxidant function. Zahedan J Res Med Sci 2016; 18(11): e4037. Doi:

18. Andrzej G, Krzysztof P. Albert Szent-Györgyi (1893-1986): The scientist who discovered vitamin C. Clinics in Dermatology 2013; 31: 327-331. doi: 10.1016/j.clindermatol. 2012.08.001.

19. Sudha JD, Reshma LR. Vitamin C: Sources, functions, sensing and analysis. Intech Open 2017. Available from http://dx.doi.org/10.5772/intechopen.70162

20. Ali AE, Eman AAE, Asmaa AG, Mohammed RZ, Mahmoud MS. The effect of vitamin $\mathrm{C}$ and/or E supplementations on type 2 diabetic adult males under metformin treatment: A single-blinded randomized controlled clinical trial. Diabetes \& Metabolic Syndrome: Clinical Research \& Reviews 2018; Available from https://doi.org/10.1016/j. dsx.2018.03.013

21. Mason SA, Bodil R, Luc JCL, Jo S, Glenn DW. Ascorbic acid supplementation improves postprandial glycaemic control and blood pressure in individuals with type 2 diabetes: Findings of a randomized cross-over trial. Diabetes Obes Metab 2019;21(3):674-685. DOI: 10.1111/dom.13571.

22. Gillani SW, Syed ASS, Mohi IMA, Mirza RB. Combined effect of metformin with ascorbic acid versus acetyl salicylic acid on diabetes-related cardiovascular complication; a 12month single blind multicenter randomized control trial. Cardiovasc Diabetol 2017; 16(103): https://doi.org/10.1186 /s12933-017-0584-9 .

23. Okafor HK, Ofoegbu HK, Nlebedim AO. Oral hypoglycemic agent and ascorbic acid supplementation therapy synergistically ameliorates blood glucose, serum lipid and inflammatory response in type 2 diabetes mellitus patients. J Anal Pharm Res 2016; 3(4): 00063. DOI: 10.15406/japlr.2016.03.00063

24. Mahmoudabadi MMS, Ali RR. Effect of EPA and vitamin C on superoxide dismutase, glutathione peroxidase, total antioxidant capacity and malondialdehyde in type 2 diabetic patients. Oman Medical Journal 2014; 29(1): 39-45. doi: 10.5001/omj.2014.09.

25. Kotb A, Khaldun MA. Effect of vitamin C on blood glucose and glycosylated hemoglobin in type II diabetes mellitus. World Journal of Analytical Chemistry 2015; 3(1A): 6-8. DOI:10.12691/wjac-3-1A-2

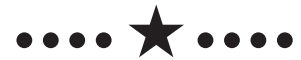

